\title{
Investigation of space flight effects on Escherichia coli and a proposed model of underlying physical mechanisms
}

\author{
David Klaus, Steven Simske, Paul Todd and Louis Stodieck \\ Author for correspondence: David Klaus. Tel: +1 303492 3525. Fax: +1 3034928883. \\ e-mail:klaus@spot.colorado.edu
}

BioServe Space

Technologies, University of Colorado, Boulder, CO

80309-429, USA

\begin{abstract}
Previous investigations have reported that space flight may produce a stimulating effect on microbial metabolism; however, the specific underlying mechanisms associated with the observed changes have not yet been identified. In an effort to systematically evaluate the effect of space flight on each phase of microbial growth (lag, exponential and stationary), a series of experiments was carried out using in vitro suspension cultures of Escherichia coli aboard seven US Space Shuttle missions. The results indicated that, as a result of space flight, the lag phase was shortened, the duration of exponential growth was increased, and the final cell population density was approximately doubled. A model was derived from these cumulative data in an attempt to associate gravity-dependent, extracellular transport phenomena with unique changes observed in each specific phase of growth. It is suggested that a cumulative effect of gravity may have a significant impact on suspended cells via their fluid environment, where an immediate, direct influence of gravity might otherwise be deemed negligible.
\end{abstract}

Keywords: Escherichia coli, space flight, gravitational biology, bacterial growth phase

\section{INTRODUCTION}

The net effect that gravity exerts at the level of the single cell is not yet clearly understood. In order to study its influence, gravity must be isolated and treated as an independent variable. Space flight offers an opportunity for investigating organism behaviour at acceleration forces substantially less than the normal $9.8 \mathrm{~m} \mathrm{~s}^{-2}$ experienced on Earth. Gravity results in a constant sedimenting force on particles, dependent on density differences with their environment. Brownian motion, or diffusion, imparts random movement to particles due to their thermal energy and is independent of gravity. Brownian motion can be theoretically described as a counterbalancing force to sedimentation in the case of particles less than about $0.5 \mu \mathrm{m}$ in diameter and below a density difference of about $0.03 \mathrm{~g} \mathrm{~cm}^{-3}$ (Todd, 1992). Escherichia coli cells suspended in an aqueous medium, therefore, can be considered to be near the threshold of the influence of gravity. Theoretical prediction of the

Abbreviations: BIMDA, BioServe/ITA materials dispersion apparatus; CGBA, Commercial Generic Bioprocessing Apparatus; CS, cell syringe; FPA, fluid processing apparatus; MDA, materials dispersion apparatus. overall outcome of weightlessness becomes uncertain at this level.

Bacterial proliferation is a function of intracellular and environmental factors. The availability of nutrients and the removal of metabolic by-products in suspension cultures are facilitated by forces acting on the cell, as well as on the bulk fluid. Gravity not only results in cell sedimentation, but also induces density-driven gradients within the bulk fluid. To attribute differences in cellular behaviour to weightlessness, both aspects of the interaction must be considered - that due to the weight of the cell and that due to changes induced in the external fluid environment; these are commonly referred to as direct and indirect effects, respectively.

Additionally, each phase of bacterial growth is governed by unique factors. The length of the lag phase when cells are inoculated into fresh medium is dependent upon changes in nutrient composition and on the age and size of the inoculum. The exponential phase is characterized by a period of population doublings in which the cells consume nutrients and excrete waste by-products. The stationary phase is initiated as nutrient and/or toxic byproduct concentrations achieve values which can no longer support the maximum rate of growth, repre- 
senting maximum cell population density (Bailey \& Ollis, 1986). The effect of space flight on bacterial growth, presumed to be primarily that of weightlessness, may result in uniquely altered growth kinetics during any or all of these phases.

Space flight experiments have been performed on a variety of organisms as documented in numerous review articles (Taylor, 1974, 1977; Tixador et al., 1981; Gmünder \& Cogoli, 1988; Alpatov et al., 1990; Cioletti et al., 1991). These reviews generally conclude that although many differences have been reported in spacegrown micro-organisms, the regulating mechanisms responsible for the changes remain, for the most part, unknown. A cursory overview of primary literature describing various space flight experiments with microorganisms indicates that inconsistencies often exist in the observed findings and interpretation of the data. Irrespective of intended experimental objectives, increased micro-organism proliferation in space has been reported by a majority of researchers (Mattoni, 1968; Tixador et al., 1985; Moatti et al., 1986; Lapchine et al., 1987, 1988; Mennigmann \& Lange, 1986; Ciferri et al., 1986). Others, however, have contradicted this finding (Bouloc \& D'Ari, 1991; Gasset et al., 1994). Specific test conditions, growth medium and assay methods may account for differing results. Reproducible, systematic evaluations are necessary to confirm these findings and determine the underlying causal factors. In this regard, the population growth characteristics of $E$. coli cultured under space flight conditions were investigated as part of a series of experiments flown onboard seven US Space Shuttle missions between April 1991 and March 1994 (STS-37, -43, -50, -54, -57, -60 and -62 ).

\section{METHODS}

Hardware and operating procedures are typically unique to specific space flight investigations and therefore must be considered an integral part of the experimental materials (Volkmann \& Behrens, 1986; Luttges, 1992). Three types of functionally similar devices were used in the seven space flight investigations reported here. Each apparatus provided initial isolation of an inoculum, sterile medium and a fixative, with subsequent serial mixing capabilities. Growth was initiated on-orbit by mixing of the inoculum and medium, and later terminated by addition of a fixative.

Organism. E. coli (ATCC 4157, original Escherich strain), was used for all of the experiments described.

Medium. Vogel-Bonner 'Medium E' minimal growth medium (Vogel \& Bonner, 1956) was used, either with or without a carbon source (glucose or ribose at $5 \mathrm{~g} \mathrm{l}^{-1}$ ). Unsupplemented Medium E (i.e. without sugar) was used as a precursor fluid to maintain the isolated cultures prior to on-orbit inoculation. The use of synthetic constituents maximized reproducibility between experiments. Following in-flight inoculation, growth was terminated at various intervals during the mission by the addition of $100 \%$ ethanol $(33 \%, v / v$, final concentration).

Flight hardware. The initial two flights (STS-37 and -43) utilized the materials dispersion apparatus (MDA) and cell syringe (CS) devices contained within the BioServe/ITA

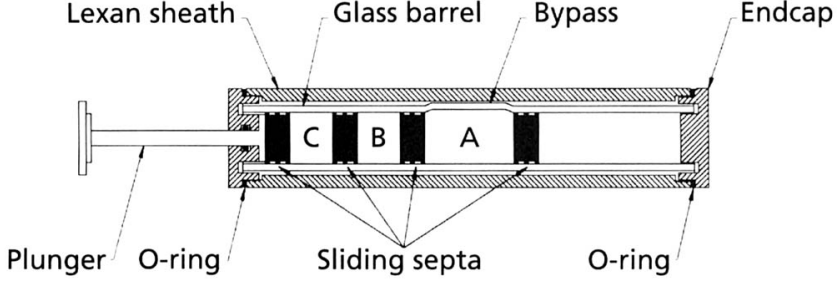

Fig. 1. Standard configuration of a fluid processing apparatus (FPA). The inner glass barrel contains three fluids initially separated by rubber stoppers. A Lexan sheath provides a second level of containment and a plunger mechanism. Experiments can be sequentially initiated and terminated by depressing the plunger handle. The fluid moves forward until it flows through the bypass into the adjacent chamber. Chambers: A, $3.5 \mathrm{ml}$ sterile growth medium; B, $0.5 \mathrm{ml} \mathrm{E}$. coli inoculum; C, $2.0 \mathrm{ml} 100 \%$ ethanol.

materials dispersion apparatus (BIMDA) payload (Holemans et al., 1991). The MDA consisted of two blocks of inert material with machined wells providing sample containment. The movement of adjacent blocks aligned opposing wells and allowed passive diffusive mixing of the contents. The CS contained the fluid samples in a glass barrel separated by rubber stoppers which was enclosed in a Lexan sheath. The fluids were actively mixed via a bypass in the glass barrel by manually depressing a plunger handle. Samples were drawn using a needle valve to pierce a rubber septum and allow fluid transfer into vials containing fixative.

On the next five missions (STS-50, $-54,-57,-60$ and -62 ), the experiments were performed in a fluid processing apparatus (FPA) as part of the Commercial Generic Bioprocessing Apparatus (CGBA) payload (Robinson et al., 1993). The FPA was conceptually similar to the CS, except that it allowed all three fluids, rather than two, to be contained and mixed within a glass barrel as illustrated in Fig. 1. Total volumes following inoculation ranged from $0.25 \mathrm{ml}$ for the MDAs to 3-4 $\mathrm{ml}$ for the CSs and FPAs.

Experimental protocol. Although timeline variations from mission to mission were inevitable, every attempt was made to treat the flight samples and ground controls within individual shuttle flights as identically as possible. Duplicate samples were prepared from a single stock culture for each flight. Cells were harvested in mid-exponential phase to maximize viability at the time of loading. From these, randomly selected samples were placed onboard the shuttle approximately $24 \mathrm{~h}$ before the scheduled launch. Because of launch delays and astronaut timeline constraints on Flight Day 1, however, inoculation did not typically occur until 2-3 d after the inoculum was originally harvested and loaded in the containers. During this time-frame, cell viability in the unsupplemented medium decreased, thus inducing a lag phase upon subsequent inoculation into fresh medium. Simultaneous ground controls were performed in flight-like hardware. They were kept vertically oriented (as if in a normal test tube) and were not mixed or stirred. The astronauts reported in-flight operations in real time, allowing synchronous initiation and termination of growth for matched ground samples to be accomplished. All samples (flight and ground) were kept in a dark, temperature-controlled environment. Particular attention was paid to maintaining comparable flight and ground control temperatures at all times. Recorded data indicated that mean temperature remained within a $\pm 2{ }^{\circ} \mathrm{C}$ tolerance between 
matched flight and ground ambient $\left(\sim 20^{\circ} \mathrm{C}\right)$ stowage and $\pm 1^{\circ} \mathrm{C}$ for the $37^{\circ} \mathrm{C}$ sample stowage. Detailed descriptions of experimental variables and flight-specific timelines are documented in Klaus (1994).

Cell populations were determined post-flight by cell counts using a Hausser Scientific Improved Neubauer Hemocytometer and/or determined from $\mathrm{OD}_{600}$ correlation using a Bausch \& Lomb Spectronic 20 (model 41A and 41D Digital Conversion) spectrophotometer with a $1 \mathrm{~cm}$ path length. Inflight optical density measurements were obtained on shuttle missions STS-50, -60 and -62 using the spectrophotometric capability $\left(\mathrm{OD}_{565}\right)$ of the CGBA flight hardware (Robinson et al., 1993).

\section{RESULTS AND DISCUSSION}

\section{Experimental results}

Cell population comparisons of multiple matched space flight and ground control samples were made following various durations of growth (Klaus et al., 1994). A synopsis of pertinent results from space flight samples and corresponding ground controls is presented here as averaged findings. Unfortunately, two sets of ground controls (16 samples) were rendered unusable during mission STS-60 due to improper temperature stowage. Extensive prior ground-based work indicated that $E$. coli growth characteristics under the experimental conditions were consistently reproducible. Therefore, in order to maintain the central theme of using direct flight and ground comparisons, only the matched samples loaded simultaneously from common starting stocks, and subsequently processed identically, are reported here. Even with the loss of two sets, the sample sizes enabled certain statistical comparisons to be made. The data obtained suggest that the specific phases of growth - lag, exponential and stationary - were differentially affected by weightlessness as follows:

Lag phase. The optical density data collected in real time at 10 min intervals during the STS-62 mission indicated that the lag phase had ended between 4 and $8 \mathrm{~h}$ earlier in the space flight samples $(n=4)$ than in the matched ground controls $(n=4)$. Limited availability for ODmonitored samples prevented statistically significant conclusions from being drawn $(P>0 \cdot 1)$. Similar findings of shortened lag phase for bacteria have also previously been reported (Mennigmann \& Lange, 1986; Manko et al., 1987), although Mennigmann \& Heise (1994) later reported that the earlier finding may have been an artifact of specific test conditions. Additionally, while not directly reported as such, interpretation of growth curve data shown by Gasset et al. (1994) and by Tixador et al. (1994) also suggests the possibility that a shortened lag phase may have occurred in space. Given the incidence of reports, however uncertain, this phenomenon warrants further investigation.

Exponential growth. A trend towards slower bacterial growth rate in space was observed, but again not found to be significantly different due to limited sample numbers collected during this phase. Population increases in flight after various durations of growth are evaluated in Table 1 using a Z-test of $\log _{10}$ (flight/ ground). Confidence intervals represent significance at $95 \%$. The relatively higher increase in population observed initially (attributed to an earlier start of division) was somewhat offset towards the latter part of exponential growth. A slower rate of growth in space may account for the 'catching up' of the ground controls during the exponential phase. The increase in difference observed again as the stationary phase was entered would coincide with a prolonged period of exponential growth in space.

In addition, optical density data indicated that the total duration of the exponential phase was increased by $2-5 \mathrm{~h}$ in space. Actual growth rate comparison was not attainable from the data due to the effect of sedimentation on ground control cells; however, based on differences between the estimated initial and measured final cell population densities relative to the total duration of the exponential phase, the deduced doubling times indicated that the space grown cultures were possibly slower than the ground controls. Not having actual counts of initial cell populations prevented accurate calculation using this method, since growth of the flight inoculum may have been altered during the time prior to initiation.

Final cell population density. Overall mean cell populations for the 40 flight and 25 ground samples successfully

Table 1. E. coli population summary of flight versus ground matched samples grown for various durations

\begin{tabular}{|lcccc|}
\hline $\begin{array}{l}\text { Days of } \\
\text { growth }\end{array}$ & $n$ & $\begin{array}{c}\text { Mean percentage } \\
\text { increase in space } \\
\text { flight } \log _{10} \\
\text { (flight/ground) }\end{array}$ & $\begin{array}{c}\text { Confidence } \\
\text { interval }(\%)^{*}\end{array}$ & $\begin{array}{l}\text { Significant } \\
\text { by Z-test? }\end{array}$ \\
\hline $0-1$ & 2 & +38 & $(5,81)$ & Yes \\
$1-2$ & 2 & +32 & $(19,45)$ & Yes \\
$2-3$ & 2 & +27 & $(-46,195)$ & No \\
$3-4$ & 12 & +49 & $(29,71)$ & Yes \\
\hline
\end{tabular}


collected at or near the stationary phase were $7 \cdot 8 \times 10^{8} \pm 3.7 \times 10^{8}$ and $4.4 \times 10^{8} \pm 2.9 \times 10^{8}$ cells $\mathrm{ml}^{-1}$, respectively. Of these comparably matched pairs, only three ground samples exceeded their flight counterparts in population density, the maximum being only by $21 \%$. The mean individual increase in space was $72 \%$ with a standard deviation of $71 \%$, which is a statistically significant difference $(P<0.05)$ by Student's $t$-test.

Data summary. The general consequences of space flight suggest the following overall effects on E. coli suspension culture growth kinetics: (1) the duration of the lag phase was decreased, (2) the rate of growth was unaffected (or slightly slower), (3) the duration of the exponential growth phase was increased, and (4) a significantly higher final cell density was achieved.

\section{Proposed model of underlying mechanisms}

From these empirical observations, a potential central relationship emerged. Namely, the reduction of gravitydependent forces in a suspension culture, such as convection and sedimentation, are presumed to alter the microenvironment surrounding a non-motile cell. This is suggested to have altered the equilibrium of extracellular mass transfer processes governing nutrient uptake and waste removal, and thus to have indirectly affected cellular metabolism. The possibility that an altered microenvironment surrounding a micro-organism may be related to changes in metabolism observed in space flight has been previously suggested (Mattoni, 1968; Planel et al., 1982). A paradox seemed to exist, however, in that this quiescent condition could simultaneously result in (1) an increased availability of nutrients due to better distribution of the cells towards the end of the growth phase, and (2) an increased local build-up of toxic by-products excreted by the cell into its microenvironment. The former intuitively supports increased growth, while the latter, an inhibitory effect. A model interpreting this 'differential effect' of weightlessness was developed from the individual responses observed in space during each phase of $E$. coli proliferation. Supporting evidence is found in related studies and theoretical analyses as follows.

Studies of protein crystal growth in space have shown the potential for forming macromolecular crystals of improved order and quality. McPherson (1993) hypothesized that this may be due to a lack of convective mixing in weightlessness, allowing a quasi-stable 'depletion zone' to form around the nucleus as the crystal grows and absorbs protein. The net effect is that the crystal surfaces interface with a solution of significantly lower protein nutrient concentration than exists in the bulk solvent, essentially creating an ideal microenvironment in which optimal growth conditions exist. Grant \& Saville (1991) theoretically examined the role of transport in protein crystal growth and concluded that, although the forces arising from natural convection were insufficient to mechanically alter the crystal, the mixing effects induced in the bulk fluid may affect crystal growth. Since bacterial proliferation in a fluid medium is also dependent upon exchanges taking place in the local environment, the possible consequences of an altered, quasi-stable microenvironment surrounding a bacterial cell were considered.

Interactions between a bacterium and its immediate environment were examined individually for each phase of growth. Beginning with the lag phase, it was noted that all suspected causes can be broadly characterized as some sort of deficiency existing either within the cell or in the extracellular medium (Barford et al., 1982). If the bulk fluid volume was effectively reduced to that of the microenvironment around the cell, the time required to condition, and/or adapt to, the smaller volume would be decreased. However, during exponential growth, an accumulation of toxic metabolic by-products, by the same principle, may be directly inhibitory and/or act indirectly by forming a pseudo-membrane (in the form of an osmotic solute gradient) interfering with nutrient flux to the cell, thus moderating growth rate. Towards the end of the exponential phase, however, the simple factor of having a more uniform distribution of cells suspended in weightlessness becomes predominant. Given sufficient nutrient availability (as is the case with $5 \mathrm{~g}$ glucose $^{-1}$ ), enhanced distribution of the cells at this point might allow prolonged growth under weightless conditions, since sedimentation occurring in normal gravity would tend to concentrate the cells on the container bottom and away from the nutrients remaining in suspension. Additionally, the local toxic byproduct concentration for the cells which had sedimented on the bottom of the container on Earth would be now increased as a result of increased cell-to-cell proximity.

Empirical observations from each phase of growth, as noted, were found to coincide with these suspected cause-and-effect relationships. To further investigate this suggested hypothesis, theoretical scale analyses were undertaken to describe the relative order-of-magnitude of forces acting on a cell. For an individual $E$. coli bacterium in suspension, the following equations examine the extracellular transport phenomena induced by sedimentation and diffusion. First, the velocity of a cell sedimenting through a fluid $\left(V_{\text {sed }}\right)$ under the influence of gravity is estimated from the Navier-Stokes equation:

$V_{\text {sed }}=2 / 9\left(\delta_{\text {particle }}-\delta_{\text {fluid }}\right)(g / \mu) a^{2}$

(Todd, 1989) where $\delta_{\text {particle }}$ is the particle density $\left(\mathrm{g} \mathrm{cm}^{-3}\right), \delta_{\text {fluid }}$ is the fluid density $\left(\mathrm{g} \mathrm{cm}^{-3}\right), \mathrm{g}$ is the acceleration due to gravity $\left(980 \mathrm{~cm} \mathrm{~s}^{-2}\right), \mu$ is the medium viscosity $\left(\mathrm{kg} \mathrm{h}^{-1} \mathrm{~m}^{-1}\right)$ and $a$ is the effective Stokes radius of the particle $(\mathrm{cm})$ defined as:

$a=(3 V / 4 \pi)^{\frac{1}{3}}$

where $V$ is the cell volume $\left(\mathrm{cm}^{3}\right)$.

For a mean E. coli cell volume of $1 \times 10^{-12} \mathrm{~cm}^{3}$ (Bailey \& Ollis, 1986), the effective Stokes radius is calculated to be $6.2 \times 10^{-5} \mathrm{~cm}$ (or $0.62 \mu \mathrm{m}$ ). A mean cell density for $E$. coli of $1.08 \mathrm{~g} \mathrm{~cm}^{-3}$ was obtained from Nanninga (1985). The density of the growth medium used was calculated 
Table 2. Relative mean distances travelled by cells and by-products from an original position at time $t=0$ due to diffusion $\langle x\rangle$ or to sedimentation $(y$ at $1 \mathrm{~g})$ shown for increasing elapsed time intervals

\begin{tabular}{|c|c|c|c|}
\hline \multirow[t]{2}{*}{ Forcing function } & \multicolumn{3}{|c|}{$\begin{array}{l}\text { Distance travelled }(\mu \mathrm{m}) \text { by cell } \\
\text { and by-products }\end{array}$} \\
\hline & $t=1 \mathrm{~s}$ & $t=1 \mathrm{~h}$ & $t=3 \mathrm{~h}$ \\
\hline Cell sedimentation $(y)$ & 0.06 & 216 & 648 \\
\hline Cell diffusion $\langle x\rangle^{*}$ & $0 \cdot 45$ & 27 & 46 \\
\hline Random swimming $\dagger$ & 28 & 1697 & 2939 \\
\hline By-product diffusion $\langle x\rangle \neq$ & $14 \cdot 1$ & 849 & 1470 \\
\hline By-product diffusion $\langle x\rangle \mathbb{S}$ & $4 \cdot 5$ & 268 & 465 \\
\hline
\end{tabular}

* $D=10^{-9} \mathrm{~cm}^{2} \mathrm{~s}^{-1}$.

$\dagger D=4 \times 10^{-6} \mathrm{~cm}^{2} \mathrm{~s}^{-1}$.

‡Assuming molecular mass $=0.5 \mathrm{kDa}, D=10^{-6} \mathrm{~cm}^{2} \mathrm{~s}^{-1}$.

\Assuming molecular mass $=40 \mathrm{kDa}, D=10^{-7} \mathrm{~cm}^{2} \mathrm{~s}^{-1}$.

to be $1.011 \mathrm{~g} \mathrm{~cm}^{-3}$. The measured viscosity of the sterile medium was approximately that of water at $1.02 \mathrm{cP}$ $\left(3.61 \mathrm{~kg} \mathrm{~h}^{-1} \mathrm{~m}^{-1}\right)$. Using these parameters, the sedimentation velocity $\left(V_{\text {sed }}\right)$ determined by equation (1) is found to be $6 \times 10^{-6} \mathrm{~cm} \mathrm{~s}^{-1}$ (or $0.06 \mu \mathrm{m} \mathrm{s}^{-1}$ ).

The distance a cell will sediment $(y)$ in a given time $(t)$ can then be found from the simple relationship:

$y=V_{\text {sed }} t$

The calculated sedimentation rate roughly concurs with measured values of $E$. coli population sedimentation. A predicted duration of $9.7 \mathrm{~d}$ for a cell to sediment $5 \mathrm{~cm}$ was observed to take $7.5 \mathrm{~d}$ from optical density measurements taken in the lab. The occurrence of flocculation could be responsible for the slightly faster than predicted rate. Of particular importance, under $1 \mathrm{~g}$ conditions, it was noted that $26 \%$ of the cell population had sedimented to the bottom just prior to the transition from exponential to stationary phase. This implies that a large fraction of cells under weightless conditions might continue to grow during this time as a result of increased access to nutrients remaining in the medium, simply due to better cell distribution in the absence of sedimentation, as hypothesized.

Independent of the unidirectional, downward settling due to gravity, random movement is imparted to particles through Brownian motion. The governing equation, as derived from Einstein's relationship, may be applied to non-motile, suspended cells:

$\langle x\rangle^{2}=2 D t$

(Todd, 1992) where $\langle x\rangle^{2}$ is the root-mean-square diffusion distance travelled $\left(\mathrm{cm}^{2}\right), D$ is the diffusion coefficient $\left(\mathrm{cm}^{2} \mathrm{~s}^{-1}\right)$ and $t$ is time $(\mathrm{s})$.

Berg \& Turner (1990) suggested an equivalent diffusion coefficient for wild-type, motile $E$. coli randomly moving to be $4 \times 10^{-6} \mathrm{~cm}^{2} \mathrm{~s}^{-1}$. This corresponds to a swim speed velocity of $\sim 3 \times 10^{-3} \mathrm{~cm} \mathrm{~s}^{-1}$ with a run interval of $1 \mathrm{~s}$ and a tumble of $0.1 \mathrm{~s}$. For non-motile cells, $D$ decreases to a value of the order of $10^{-9} \mathrm{~cm}^{2} \mathrm{~s}^{-1}$, as determined by the Stokes-Einstein equation:

$D=\left(k_{\mathrm{B}} T\right) /(6 \pi \mu a)$

where $k_{\mathrm{B}}$ is the Boltzmann constant $\left(1.38 \times 10^{-23} \mathrm{~J} \mathrm{~mol}^{-1}\right.$ $\left.\mathrm{K}^{-1}\right), T$ is the temperature $(\mathrm{K}), \mu$ is the medium viscosity $\left(\mathrm{kg} \mathrm{m}^{-1} \mathrm{~s}^{-1}\right)$ and $a$ is the effective Stokes' radius, defined above $(0.62 \mu \mathrm{m})$.

A range of diffusion coefficients for the cellular byproducts was assumed to be of the order of $10^{-7}-10^{-6} \mathrm{~cm}^{2} \mathrm{~s}^{-1}$, roughly corresponding to molecular masses of 40 and $0.5 \mathrm{kDa}$, respectively. Mean distances travelled for the cell and assumed by-products due to diffusion $\langle x\rangle$ and sedimentation $(y$, at $1 \mathrm{~g})$ after specified time intervals are given in Table 2. The E. coli strain used was not observed (microscopically) to exhibit regular swimming behaviour under the test conditions used, therefore it was assumed that the cells were nonmotile in space as well, and only moving as a result of Brownian motion. Cell movement due to random swimming would likely alter the outcome and is included for comparison purposes only.

Cellular movement through the medium becomes important if one considers a bacterium to be a point source excreting metabolic waste, with a sphere of decreasing by-product gradients extending radially outward from the cell. The average radius of the unstirred sphere is a function of the root-mean distance $\langle x\rangle$ that the excreted substances have diffused away from their point of origin. In a $1 g$ environment, external fluid mixing and cell sedimentation would each serve to disrupt the continuity of this sphere. Since convective fluid mixing and cell sedimentation are absent in the quiescent environment encountered during space flight, it is reasonable to assume that a sphere of waste by-products may accumulate around the cell and remain somewhat stable (Albrecht-Buehler, 1991). 
This hypothesized zonal accumulation of metabolic byproducts surrounding a cell under weightless conditions is suggested to be dependent upon the ratio of the distance that the cell would have normally 'fallen away' from its waste, relative to the distance that the byproducts are simultaneously able to 'diffuse away' from the cell. In other words, does the cell 'fall' out of the sphere created from its own excreted waste? Or more specifically, in the absence of sedimentation, does the cell remain in the vicinity of a substantially increased concentration of excreted by-products for a period of time sufficient to elicit a metabolic response?

A ratio comparing the distance that a cell will sediment to that which its by-products will diffuse away in the same timeframe can be used to ascertain the relative contributions of each motion towards 'getting the cell away from its excretions'. At $t=1 \mathrm{~s}$ (Table 2), the cell has 'fallen' a distance $(y)$ of only $0.06 \mu \mathrm{m}$, while the excreted metabolic by-products (assuming $D=10^{-7} \mathrm{~cm}^{2}$ $\mathrm{s}^{-1}$ ) have diffused somewhere into a sphere of mean radius $\langle x\rangle$ estimated to be $4.5 \mu \mathrm{m}$. The corresponding ratio $[R=$ (distance cell has fallen)/(distance waste has diffused)] is 0.013 . From this relatively small value, it initially appears that cell sedimentation does not contribute significantly towards movement away from the original location of the centre of the sphere when compared to the distance the by-products have diffused away in the same time. Hence, one could be led to believe that gravity is not a significant force acting on the cell. However, since sedimentation is linear and diffusion is a function of a square root, the relative contribution of sedimentation steadily increases. After a period of $1 \mathrm{~h}$ (Table 2), the cell is now calculated to have sedimented a distance of $216 \mu \mathrm{m}$, while these same byproducts have diffused radially outward an average of $268 \mu \mathrm{m}$. $R$ thus increases to $0 \cdot 81$. After $3 \mathrm{~h}$, the estimated $R$ is shown to be 1.40 . At this point $(R>1)$ it becomes apparent that cell sedimentation may substantially contribute towards separating the bacterium from its by-products, relative to the simultaneous removal of the by-products via diffusion. Under weightless conditions, therefore, it is likely that the absence of this cumulative sedimentation effect, which disrupts the sphere of excreted by-products, may modify the immediate environment of the cell enough to influence its metabolism.

Exposure of a cell to this chemically altered environment must be of sufficient duration to elicit a metabolic response. In this case, the $3 \mathrm{~h}$ interval corresponds to the approximate doubling time of the bacteria in the minimal medium used for these tests. Therefore, it seems probable that exposure to medium conditions that had been altered over a period of $3 \mathrm{~h}$ would be adequate to impact metabolic processes. Determination of actual by-products and their rates of production is necessary to ascertain a more exact relationship; however, the by-product diffusion coefficients $\left\langle 10^{-7}\right.$ and $10^{-6} \mathrm{~cm}^{2} \mathrm{~s}^{-1}$ ) used for this analysis were assumed to reflect probable upper and lower limits.

The medium-dependent responses to space flight suggested by Mennigmann \& Heise (1994) may, as a consequence, be related to the specific growth kinetics unique to the experimental conditions. Both factors, growth rate and by-product formation, are important variables for the hypothesized zonal accumulation phenomenon, and both are medium dependent as well. Containment geometry must also be considered. A long, flat container configured horizontally in $1 \mathrm{~g}$ may not provide a sufficient distance for the cell to 'fall', thereby minimizing the likelihood of the above-mentioned 'zonal accumulation' effects manifesting themselves. Therefore, one possibly might not expect any observable differences in space flight results when compared to 'long, flat' ground controls. Simple lab experiments (unpublished data) have, in fact, shown that E. coli cultures grown in $9 \mathrm{ml}$ vials placed horizontally fare better in contrast to matched, vertical cultures. The cumulative nature of the mechanisms described may require sufficient time for sedimentation to occur in order to elicit the suggested response of altered growth kinetics.

\section{Conclusions}

It is suggested that a cumulative effect of gravity may prove to have a significant impact on suspended cells via their fluid environment, where an immediate, direct influence of gravity might otherwise be deemed negligible. While the data presented here do not offer conclusive evidence of the underlying mechanisms associated with the observed space flight effects on bacterial proliferation, specific, testable hypotheses can be evolved from relationships posed. Theoretical analyses exemplify a framework for analysing probable effects of weightlessness on suspended cells. The important parameters suggested for consideration are summarized as follows: (1) ratio of cell sedimentation relative to the diffusion rate of by-products, nutrients, and the cell itself; (2) expected duration required for an altered microenvironment to elicit a metabolic response; and (3) specific data pertaining to actual by-product composition and excretion rates. Testing under various environmental conditions (e.g. stirred or unstirred, horizontal or vertical containment, hyper- $\boldsymbol{g}$, and clinorotation) can provide additional data to assist in further isolating the hypothesized effects resulting from an altered microenvironment surrounding a cell.

\section{ACKNOWLEDGEMENTS}

Research and space flight opportunities were supported by BioServe Space Technologies at the University of Colorado under NASA Grant NAGW-1197. Follow-on data analysis and publication efforts were supported by the Fulbright Commission and graciously made possible through the use of facilities at the DLR-Institute for Aerospace Medicine in Cologne, Germany. This paper is written in dedication to the late Dr Marvin Luttges.

\section{REFERENCES}

Albrecht-Buehler, G. (1991). Possible mechanisms of indirect gravity sensing by cells. Am Soc Grav Space Biol Bull 4, 25-34. 
Alpatov, A. M., Il'in, Y. A., Antipov, V. V. \& Tairbekov, M. G. (1990). Space biology and medicine biological experiments on COSMOS-1887. In USSR Space Life Sciences Digest NASA Contractor Report [NASA publication 3922(31)], pp. 74-77. Edited by L. R. Stone, M. A. Frey, R. Teeter, V. Garshnek \& J. Rowe. Washington, DC: NASA.

Bailey, J. E. \& Ollis, D. F. (1986). Biochemical Engineering Fundamentals, 2nd edn. New York: McGraw-Hill.

Barford, J. P., Pamment, N. B. \& Hall, R. J. (1982). Lag phases and transients. In Microbial Population Dynamics, pp. 56-87. Edited by M. J. Bazin. Boca Raton, FL: CRC.

Berg, H. C. \& Turner, L. (1990). Chemotaxis of bacteria in glass capillary arrays. Biophys $J$ 58, 919-930.

Bouloc, P. \& D'Ari, R. (1991). Escherichia coli metabolism in space. $J$ Gen Microbiol 137, 2839-2843.

Ciferri, O., Tiboni, O., DiPasquale, G., Orlandoni, A. M. \& Marchesi, M. L. (1986). Effects of microgravity on genetic recombination in Escherichia coli. Naturwissenschaften 73, 418-421.

Cioletti, L. A., Pierson, D. L. \& Mishra, S. K. (1991). Microbial growth and physiology in space: a review. Society of Automotive Engineers International Technical Paper 911512, 1-11. Warrendale, PA: SAE Publications.

Gasset, G., Tixador, R., Eche, B., Lapchine, L., Moatti, N., Toorop, P. \& Woldringh, C. (1994). Growth and division of Escherichia coli under microgravity conditions. Res Microbiol 145, 112-120.

Gmünder, F. K. \& Cogoli, A. (1988). Cultivation of single cells in space. Appl Microgravity Technol I 3, 115-122.

Grant, M. L. \& Saville, D. A. (1991). The role of transport phenomena in protein crystal growth. J Cryst Growth 108, 8-18. Holemans, J., Cassanto, J. M., Moller, T. W., Cassanto, V. A., Rose, A., Luttges, M., Morrison, D., Todd, P., Stewart, R., Korszun, R. Z. \& Deardorff, G. (1991). The BIMDA shuttle flight mission: a low cost microgravity payload. Microgravity $Q 1,235-247$.

Klaus, D. M. (1994). Effects of space flight on the growth and development of Escherichia coli. $\mathrm{PhD}$ thesis, University of Colorado.

Klaus, D. M., Luttges, M. W. \& Stodieck, L. S. (1994). Investigation of space flight effects on Escherichia coli growth. Society of Automotive Engineers International Technical Paper Series SAE 941260. Warrendale, PA: SAE Publications.

Lapchine, L., Moatti, N., Richoilley, G., Templier, J., Gasset, G. \& Tixador, R. (1987). Antibiotic activity in space, results and hypothesis. Proceedings of the 3rd European Symposium on Life Sciences Research in Space (European Space Agency publication SP-271), pp. 305-306. Paris: European Space Agency.

Lapchine, L., Moatti, N., Richoilley, G., Templier, J., Gasset, G. \& Tixador, R. (1988). The antibio experiment. In Biorack on Spacelab D1 (European Space Agency publication SP-1091), pp. 45-51. Paris: European Space Agency.

Luttges, M. W. (1992). Recognizing and optimizing flight opportunities with hardware and life sciences limitations. Trans Kansas Acad Sci 95, 76-86.

McPherson, A. (1993). Effects of a microgravity environment on the crystallization of biological macromolecules. Microgravity Sci Technol 1/2, 101-109.

Manko, V. G., Kordyum, V. A., Vorob'yev, L. V., Konshin, N. I. \& Nechitaylo, G. S. (1987). Changes over time in Proteus vulgaris cultures grown in the ROST-4M2 device on the 'Salyut-7' space station. In USSR Space Life Sciences Digest NASA Contractor
Report [NASA publication 3922(14)], pp. 70-73. Edited by L. R. Hooke, M. Radtke \& R. Teeter. Washington, DC: NASA.

Mattoni, R. H. T. (1968). Space-flight effects and gamma radiation interaction on growth and induction of lysogenic bacteria. BioScience 18, 602-608.

Mennigmann, H. D. \& Heise, M. (1994). Response of growing bacteria to reduction in gravity. Proceedings of the 5th European Symposium of Life Sciences Research in Space, (European Space Agency publication SP-366), pp. 83-87. Paris: European Space Agency.

Mennigmann, H. D. \& Lange, M. (1986). Growth and differentiation of Bacillus subtilus under microgravity. Naturwissenschaften 73, 415-417.

Moatti, N., Lapchine, L., Gasset, G., Richoilley, G., Templier, J. \& Tixador, R. (1986). Preliminary results of the 'antibio' experiment. Naturwissenschaften 73, 413-414.

Nanninga, N. (1985). Molecular cytology of Escherichia coli. Orlando, FL: Academic Press.

Planel, H., Tixador, R., Nefedov, Y., Gretchko, G. \& Richoilley, G. (1982). Effects of space flight factors at the cellular level: results of the cytos experiment. Aviat Space Environ Med 53, 370-374.

Robinson, M. C., Luttges, M. W. \& Stodieck, L. S. (1993). Commercial generic bioprocessing apparatus. American Institute for Aeronautics and Astronautics Space Programs and Technologies Conference. AIAA 93-4314. Washington, DC: AIAA.

Taylor, G. R. (1974). Space microbiology. Annu Rev Microbiol 28, 121-137.

Taylor, G. R. (1977). Cell biology experiments conducted in space. BioScience 27, 102-108.

Tixador, R., Richoilley, G., Raffin, J., Bost, R., Kojarinov, V. \& Lepskye, A. (1981). The Cytos biological experiments carried out on the soviet orbital station Salyut 6. Aviat Space Environ Med 52, 485-487.

Tixador, R., Richoilley, G., Gasset, G., Templier, J., Bes, J. C., Moatti, N. \& Lapchine, L. (1985). Study of minimal inhibitory concentration of antibiotics on bacteria cultivated in vitro in space (Cytos 2 experiment). Aviat Space Environ Med 56, 748-751.

Tixador, R., Gasset, G., Eche, B., Moatti, N., Lapchine, L., Woldringh, C., Tooprop, P., Moatti, J. P., Delmotte, F. \& Tap, G. (1994). Behavior of bacteria and antibiotics under space conditions. Aviat Space Environ Med 65, 551-556.

Todd, P. (1989). Gravity-dependent phenomena at the scale of the single cell. Am Soc Grav Space Biol Bull 2, 95-113.

Todd, P. (1992). Gravity and the mammalian cell. In Physical Forces and the Mammalian Cell, pp. 347-381. Edited by J. Frangos \& C. Ives. New York: Academic Press.

Vogel, H. J. \& Bonner, D. M. (1956). Acetylornithinase of Escherichia coli: partial purification and some properties. $J$ Biol Chem 218, 97-106.

Volkmann, D. \& Behrens, H. M. (1986). Flight hardware for chemical fixation of living material in the microgravity environment. Naturwissenschaften 73, 435-437.

Received 14 May 1996; revised 20 August 1996; accepted 16 September 1996. 